\title{
REWARDS AND ORGANIZATIONAL COMMITMENT ACROSS STRUCTURAL CHARACTERISTICS: A META-ANALYSIS
}

\author{
Aaron Cohen \\ University of Haifa, Israel \\ Urs E. Gattiker \\ The University of Lethbridge, Alberta, Canada
}

\begin{abstract}
This article uses meta-analysis to summarize previous empirical studies which examine the relationship between actual income/pay satisfaction and organizational commitment (OC) across different structural settings. Twenty-one studies with correlational data on the relationship between OC and income, and 27 studies dealing with $\mathrm{OC}$ and pay satisfaction are examined; these studies include 23 and 31 independent samples, respectively. The findings reveal a moderator effect related to type of occupation in the OC-income relationship, and to sector in the OC-pay satisfaction relationship. The findings also show the moderating effect of measurement of $\mathrm{OC}$ on pay satisfaction. Theoretical and methodological considerations pertaining to the OC-rewards relationship are discussed. Directions for future research and practical implications are indicated.
\end{abstract}

In the past two decades, the concept of organizational commitment (OC) has grown in popularity in the literature of industrial/organizational psychology and organizational behavior (Mathieu \& Zajac,1990). Managers and researchers have focused on OC because it has been shown to be a predictor of important organizational outcomes such as turnover, absenteeism, and tardiness (e.g., Angle \& Perry, 1981; Cohen, 1991; Mowday, Porter \& Steers 1982). OC is a relatively stable attitude; it can be defined as a strong belief in, and acceptance of, the organization's goals and values, a willingness to exert considerable effort for the

The authors would like to thank HelenJane Shawyer and Marion Lupu for their editorial assistance.

Comments should be addressed to Aaron Cohen, Department of Political Science, The University of Haifa, Mount Carmel, Haifa 31 905, Israel. 
firm and a strong desire to remain in the organization (Porter, Steers, Mowday \& Boulian, 1974).

One issue that has gained considerable attention in the literature is how reward allocations, such as income, may relate to attitudes such as OC (Mowday, Porter \& Steers, 1982; Oliver, 1990a, 1990b). Rewards are factors over which the organization has apparent control and can, therefore, allocate differentially to those employees who contribute more toward achieving organizational goals. Extrinsic reward allocations, such as income, are considered an investment that will increase OC levels and prevent turnover (Becker, 1960). Rewards are one of the components of the exchange relationships between employee and organization (Mowday, Porter \& Steers, 1982). The exchange theory reasons that employees offer commitment in return for intrinsic and extrinsic rewards from the organization.

Using meta-analyses, Cohen and Lowenberg (1990), as well as Mathieu and Zajac (1990), reported a modest mean weighted correlation between $\mathrm{OC}$ and actual income of $r=.19$ and $r=.18$ respectively. Mathieu and Zajac (1990) also found a mean correlation of $r=.31$ between pay satisfaction and OC. These main effect findings show the limited effect of rewards, especially that of actual income on OC. Mathieu and Zajac (1990) reported that the possibility of moderator effects could not be ruled out for almost all of the 48 correlates of $\mathrm{OC}$ examined in their meta-analysis. Surprisingly, however, one finds little empirical research, and few proposed conceptual models, of any of the moderating effects on the relationships between $O C$ and its antecedents. Most of the existing reviews, particularly in the industrial psychology literature examining the relationship between reward variables and OC (e.g., Cohen \& Lowenberg,1990; Mathieu \& Zajac, 1990) are based on main effect analysis. However, as Guzzo, Jackson and Katzell (1987) have pointed out, "one of the most exciting promises of meta-analysis is that it allows the reviewer to determine the effects of moderators that have never been examined in an original empirical study" (p. 414).

Recent developments in meta-analysis (Hunter, Schmidt \& Jackson, 1982; Hunter \& Schmidt, 1990) have made it possible to reexamine existing studies using quantitative review methods. Such methods permit the statistical aggregation of research findings and the systematic assessment of inter-study moderators. Given the limited amount of research that has examined the OC-rewards relationship across structural settings and occupations, a meta-analysis review appears to be conceptually and practically appropriate. The findings of this study may clarify whether structural characteristics such as industry sector, size of organization, occupation and position (e.g., manager vs. non-manager) moderate the relationship between $\mathrm{OC}$ and reward variables. Also, the data permit the testing of whether particular theoretical mechanisms 
and models are more valid for certain structural settings. From a human resource management (HRM) perspective, if the OC-reward relationship varies across structural settings, then attempts to increase levels of OC should differ correspondingly. This understanding may allow for more effective reward programs and may also suggest certain income allocation strategies, thereby increasing OC in employees. Such data would also provide managers with more accurate explanations regarding the behavior of their subordinates and themselves on the job.

\section{LITERATURE REVIEW AND HYPOTHESES: TESTING FOR MODERATORS}

Researchers in numerous disciplines have become increasingly interested in how reward systems may affect attitudes (e.g., Fahr, Griffeth \& Balkin, 1991). It is of particular interest how objective (income) and subjective (pay satisfaction) indicators of rewards may relate with $\mathrm{OC}$. Pay satisfaction and $\mathrm{OC}$ are in part the result of information processing which may include a valuation of environmental attributes such as pay and one's job. In this context, valuation refers to cognitive appraisals of environmental attributes in terms of schemes derived from values such as equity and justice (Mandler, 1982; Greenberg, 1982). Thus the valuation process results in a cognitive meaning of the situation (e.g., pay) which can lead to pay satisfaction or dissatisfaction. The above discussion raises the issue of whether a person's pay (or pay satisfaction) relates to the level of OC. Data about this information would indicate how much actual pay and/or pay satisfaction may relate with $\mathrm{OC}$, thereby suggesting certain pay allocation strategies to a manager for increasing employees' OC levels.

\section{Industry Sector}

Based on the exchange theory, Wiener and Vardi (1980) proposed a specific explanation as to how the type of organization moderates the relationships between reward variables and OC. They argued that organizations differ in the primary mechanisms used to control the work behavior of their members. In private organizations, the primary mechanism is based on calculative-instrumental processes, since the essence of a member's involvement and "contract" with the organization is economic and incentive-oriented.

Wiener and Vardi's (1980) explanation suggests that in private firms rewards are an important factor in an employee's OC. In public organizations, however, OC will be affected by other variables such as personal values, working conditions, and job characteristics. Some indi- 
rect support for this line of reasoning comes from research which reports that public organizations tend to pay higher wages than their private counterparts (e.g., Hundley, 1991; Moulton, 1990) although attitudes are not necessarily more positive than in private firms (e.g., Nollen \& Gaertner, 1991). Thus, the moderating effect of rewards (extrinsic and intrinsic) on the $\mathrm{OC}$ outcome should be significant, and suggests the testing of the following hypothesis:

\section{Hypothesis 1: The relationship between reward variables and $O C$ will be} stronger in private- than in public-sector organizations.

\section{Organization Size}

In contrast to small firms, large organizations offer fewer opportunities for employees to develop an identification with the organization, thus increasing possible alienation (Hodson \& Sullivan, 1985). Income would be an important factor affecting OC in large organizations, because informal mechanisms that give an employee the opportunities to develop his/her identification with the firm are scarce. Support for this line of reasoning comes from data which demonstrate that observationally similar workers employed by large organizations earn more than their smaller counterparts. On average, employees of large firms are paid salaries that are between $12 \%$ (e.g., Pearce, 1990) and 39\% (Idson \& Feaster, 1990) higher.

Distributive justice is related to outcome satisfaction (e.g., with pay) (cf. Fryxell \& Gordon, 1989). Larger firms with internal labor markets, which have explicit rules and regulations pertaining to job classifications and ranges of remuneration, are more likely to have pay satisfaction relate to OC levels (cf. Pfeffer \& Cohen, 1989). In small firms, job and pay classifications and their link to actual remuneration packages are not always as clear. Moreover, factors other than pay-related rewards, such as social relationships and more informal and personal communication, will have a strong effect upon OC (Hodson \& Sullivan, 1985). This suggests the testing of the following hypothesis:

Hypothesis 2: The relationship between reward variables and $O C$ will be stronger in larger organizations than in smaller ones.

\section{Type of Occupation and Level in Organizational Hierarchy}

Occupations are another moderator of the reward commitment relationship insofar as occupations represent a certain status and privilege for various groups of workers. Wiener and Vardi (1980) argued that in some positions, for example, incentive-oriented "contract" can be emphasized by paying a blue-collar worker a piece rate. Accordingly, for 
professionals, the economic "contract" is less pronounced and, therefore, normative considerations assume a more important role in controlling work behavior.

Similarly, managers tend to be more committed than non-managerial employees for reasons such as higher income (e.g., Grusky, 1966). Supervisory positions are a reward from the organization providing the individual with more status, autonomy and a higher quality of worklife. In contrast, for employees in lower status occupations and non-managerial positions, income and pay satisfaction would be important factors for moderating $\mathrm{OC}$ levels for two reasons (1) intrinsic rewards such as responsibility and quality of work life are limited; and (2) their actual income is lower than those in higher status occupations and jobs. Rewards (actual and perceived) may be considered as important determinants of OC (Oliver, 1990; Salancik, 1977a, 1977b). This suggests the testing of the following hypothesis:

Hypothesis 3: The relationship between reward variables and $O C$ will be stronger for employees in lower status occupations and positions than for employees in higher status ones (e.g., blue-collar versus white-collar).

\section{METHOD}

Meta-analysis procedures as suggested by Hunter, Schmidt and Jackson (1982) and Hunter and Schmidt (1990) were used in this study because they aggregate correlation coefficients across studies, correct for the presence of statistical artifacts and provide unbiased estimates of the theoretical population relationships. Following this method, the present study consists of three basic steps:

1) the estimation of population mean correlations and variance;

2) the correction for statistical artifacts; and

3) the analysis of moderating effects.

Published studies (1967-1991) were identified by means of both manual and computer-assisted searches of the social science, psychology and managerial literature. The computer search scanned the PsycInfo and Management Contents data bases. The manual search entailed an article by article search which was performed for 24 organizational behavior, psychological and sociological journals. Of the studies that were reviewed, 21 included correlational data dealing with the relationships between $\mathrm{OC}$ and income, while 27 included data on $\mathrm{OC}$ and pay satisfaction. These studies consisted of 31 and 23 independent samples, respectively. A list of the studies for the two variables is presented in the Appendix. 
Several additional points need to be emphasized to clarify the metaanalysis. Statistical artifacts controlled for in this meta-analysis included sampling error and predictor unreliability. No corrections were made for range restrictions because of insufficient data. Regarding the rules for rejecting the situational specificity hypothesis, it was decided to follow the Pearlman, Schmidt and Hunter (1980) rule of 75\%, along with the Mathieu and Zajac (1990) argument that when only two factors are corrected in the meta-analysis, a lower percentage of artifactual variance, $50 \%-60 \%$ for example, is appropriate. The chi square test of the significance of the variance across the studies remaining after corrections for artifacts (Hunter and Schmidt, 1990) was used as supporting evidence. It was also decided to adopt Schmidt, Hunter and Raju's (1988) suggestion that confidence intervals should be used to determine the validity of the data and if the data permit one to generalize.

\section{Definition of Variables}

Definition of Sector. The total sample was divided into two subgroups; samples that were based on private sector organizations and samples that were based on government, municipal and other public organizations. Mixed samples that included both public and private organizations were omitted from the analysis and defined as missing values.

Definition of Size. The total sample was divided into two subgroups. Organizations that were reported in the method section of each sample as small or medium size were included in the first subgroup. Organizations that were reported as large were included in the second subgroup. Mixed samples that include both small/medium and large organizations were omitted from the analysis and were defined as missing values.

Definition of Occupational Groups. The total sample was divided into two main occupational groups: white-collar employees and blue-collar employees. Blue-collar employees included unskilled, semi-skilled and skilled. The data available did not enable a more detailed categorization of blue-collar employees. White-collar employees were categorized into two subgroups. Professionals and semi-professionals constituted one subgroup (e.g., scientists, engineers, nurses, accountants). Clerical (clerical and administrative staff) formed the second subgroup. This categorization allowed the expectations regarding the OC-rewards relationships to be treated in two comparisons: (1) one between blue-collar (lower status occupations) and white-collar (higher status occupations relative to blue-collar) employees should reveal stronger relationships for blue-collar workers. (2) A comparison between the two white-collar subgroups, clerical (lower status occupations) and professionals (higher status occupations) should reveal stronger relationships for clerical 
workers. Mixed samples were omitted from the analysis and defined as missing values.

Definition of Level. The total sample was divided into two subgroups. The first included all samples that reported only managers and supervisors. The second included samples that included only non-managers. Mixed samples were omitted from the analysis and were defined as missing values.

\section{Commitment and Pay Satisfaction Measures}

The methodological consideration controlled for in this study were the measurement of $\mathrm{OC}$ and pay satisfaction. Controlling for the moderating effects of the different measures of $\mathrm{OC}$ and pay satisfaction allowed for comprehensive control of the methodological aspects of the OC-rewards relationships. With regard to the measures of OC, three types were controlled for in this study. Following Randall (1990), it was decided to differentiate between the common OCQ (Organizational Commitment Questionnaire) of Porter, Steers, Mowday \& Boulian (1974), and other attitudinal measures that were not $\mathrm{OCQ}$, such as the measure proposed by Meyer and Allen (1984, 1988). Additionally, following Mathieu and Zajac (1990) it was decided to control for the "side-bet" calculative measures based on Ritzer and Trice's (1969) scale. Two types of pay satisfaction measures were controlled for in this study, namely, the common Job Descriptive Index (JDI) of Smith, Kendall and Hulin, (1969) and all other measures of pay satisfaction, some of which were one item measure or measures developed by the authors.

\section{Moderator Effects}

In the moderator analysis, a moderating effect will be shown in two ways: (1) the average correlation will vary from subgroup to subgroup, and (2) the corrected variance average will be lower in the subgroups than for the data set as a whole (Hunter, Schmidt \& Jackson, 1982). Hunter and Schmidt (1990, Chapter 9) provide a statistical procedure for detecting a moderator among binary variables. First, the overall meta-analysis should be split into two subgroups based on the moderator variable. Then, a meta-analysis should be performed within each subgroup of studies. If the correlations of the different subgroups differ in the predicted direction, this is confirming support for the predicted moderator variable. However, Hunter and Schmidt (1990, Chapter 9) suggest that an observed difference between means (i.e., subgroup correlations) may also be due to a second order sampling error. If a metaanalysis is based on many studies, then there is little sampling error in meta-analytic estimates. However, if it is based on only a few studies, 
then there will be sampling error in estimating the means and standard deviations. This type of error is called second order sampling error.

Hunter and Schmidt (1990, Chapter 9) maintain that the range of potential sampling error in each subgroup of studies can be estimated by computing a confidence interval for the mean correlation in each subgroup. To the extent that these confidence intervals do not overlap, it is a clear confirmation of the predicted moderator variable. Hunter and Schmidt (1990, Chapter 9) suggest that the way to measure the extent of overlap between the confidence intervals is to compute a significance test on the difference between the two mean correlations. The formula for the significance test is:

$$
z=C / \sqrt{\operatorname{var}(c)}
$$

where $\mathrm{C}$ is the difference between the correlations; $\operatorname{var}(\mathrm{c})=\mathrm{S}_{1}{ }^{2}+\mathrm{S}_{2}{ }^{2}$ where $S_{1}{ }^{2}$ is the variance of observed effect sizes divided by the number of samples for the specific subgroup and $\mathrm{S}_{2}{ }^{2}$ is the same as $\mathrm{S}_{1}{ }^{2}$ for its subgroup. For the present study, Hunter and Schmidt's (1990) procedure was used to examine the significance of the differences between the subgroup correlations.

\section{RESULTS}

To facilitate the presentation of the data, the following section will present the results in three sections as given by Hypotheses 1 through 3.

Sector as a Moderator of $O C$. Hypothesis 1 states that the relationship between reward variables and OC would be stronger in private organizations than in their public counterparts.

Actual Income. Table 1 presents the relationship between income and OC for the total sample and controls for the sector and the size of the organization. For actual income (see Table 1) the data indicate that the relationship between income and $\mathrm{OC}$ is stronger for private firms ( $r=$ .15) than for public organizations $(r=.06)$. Although the correlations are in the direction predicted, the difference between the two correlations is not significant $(z=.60 ; p>.05)$. Accordingly, these data provide only a weak support for Hypothesis 1 .

Pay Satisfaction. Table 2 presents the relationship between pay satisfaction and $\mathrm{OC}$ controlled for sector and size of the firm. The relationship between pay satisfaction and $\mathrm{OC}$ is stronger in private organizations $(r$ $=.45)$ than in public organizations $(r=.12)$. The difference between the correlations is significant $(z=3.96 ; p<.05)$ and thus provides strong support for Hypothesis 1. 


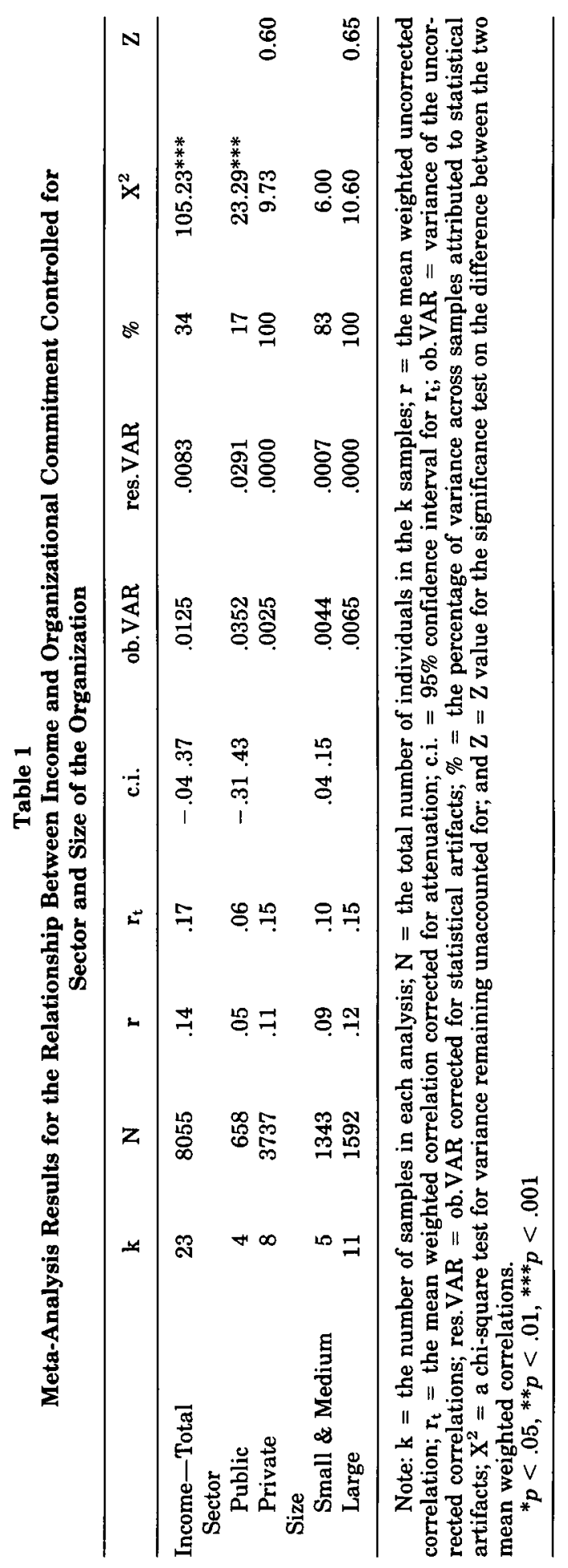


Size as a Moderator of $O C$. Hypothesis 2 predicts that the relationship between $\mathrm{OC}$ and reward variables would be stronger for large organizations than for smaller and medium-sized ones.

Actual Income For actual income (see Table 1) the data indicate that the relationship between income in large firms is higher than in small and medium-sized ones ( $r=.15$ vs. $r=.10$ ). These findings are in accordance with the expectation that the relationship between actual income and $\mathrm{OC}$ would be stronger in larger organizations. However, the difference between the $r$ 's for large and small firms is not significant $(z=.65$; $p>.05$ ), and therefore the null hypothesis is not rejected.

Pay Satisfaction. Results in Table 2 regarding the size of the organization as a moderator contradict Hypothesis 2. The pay satisfaction-OC relationship is stronger for small and medium-size organizations $(r=$ .30) than for large ones $(r=.23)$. Again, this difference is not significant $(z=.72 ; p>.05)$. Accordingly, the null hypothesis is not rejected when testing the relationship between pay satisfaction and organizational commitment when controlling for organization size.

Occupation and Hierarchical Level as Moderators of OC. Hypothesis 3 predicts that the relationship between $\mathrm{OC}$ and reward variables would be stronger for employees in lower status positions (e.g., blue collar, clerical employees).

Actual Income. Results in Table 3 contradict Hypothesis 3. The results show that this relationship is stronger for white-collar $(r=.21)$ than for blue-collar employees $(r=.09)$. However this difference is not significant $(z=1.01 ; p>.05)$.

As shown in Table 3, the data indicate that the income-OC relationship is higher for professionals $(r=.30)$ than for clerical workers $(r=.01)$. The difference between the correlations is significant $(z=4.15$; $p<.05)$ and thus permits us to reject the null hypothesis. However, the findings are the reverse of those predicted by Hypothesis 3 .

The income-OC relationship is also stronger for managers $(r=.17)$ than for non-managers $(r=.11)$. However, the difference is not significant for the professionals vs clerical employees comparison $(z=0.13$; $p>.05$ ). These data suggest that, except for the difference between professionals and clerical white-collar workers, we fail to reject the null hypothesis that the relationship between income and commitment for lower status employees is not significantly greater than for higher-status workers.

Pay Satisfaction. Results in Table 4 provide weak support for Hypothesis 3 . The relationship between pay satisfaction and $\mathrm{OC}$ is stronger for blue-collar $(r=.37)$ than for white-collar $(r=.24)$ employees. However, 


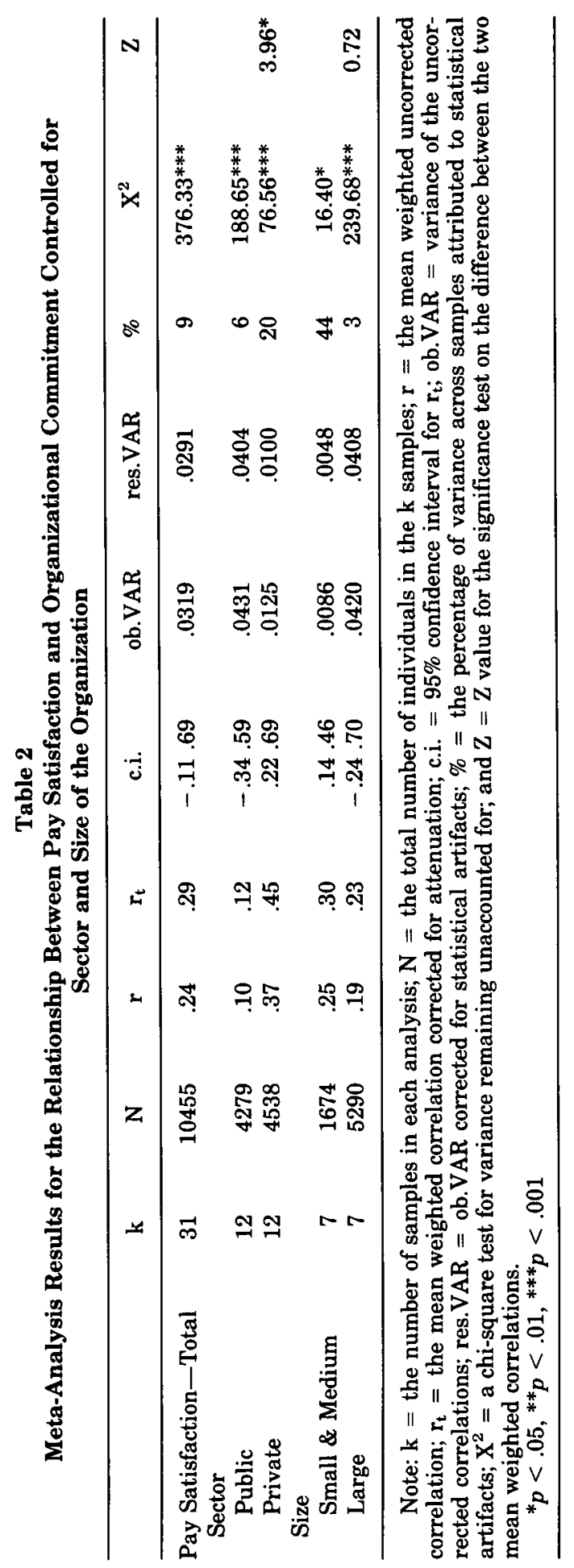




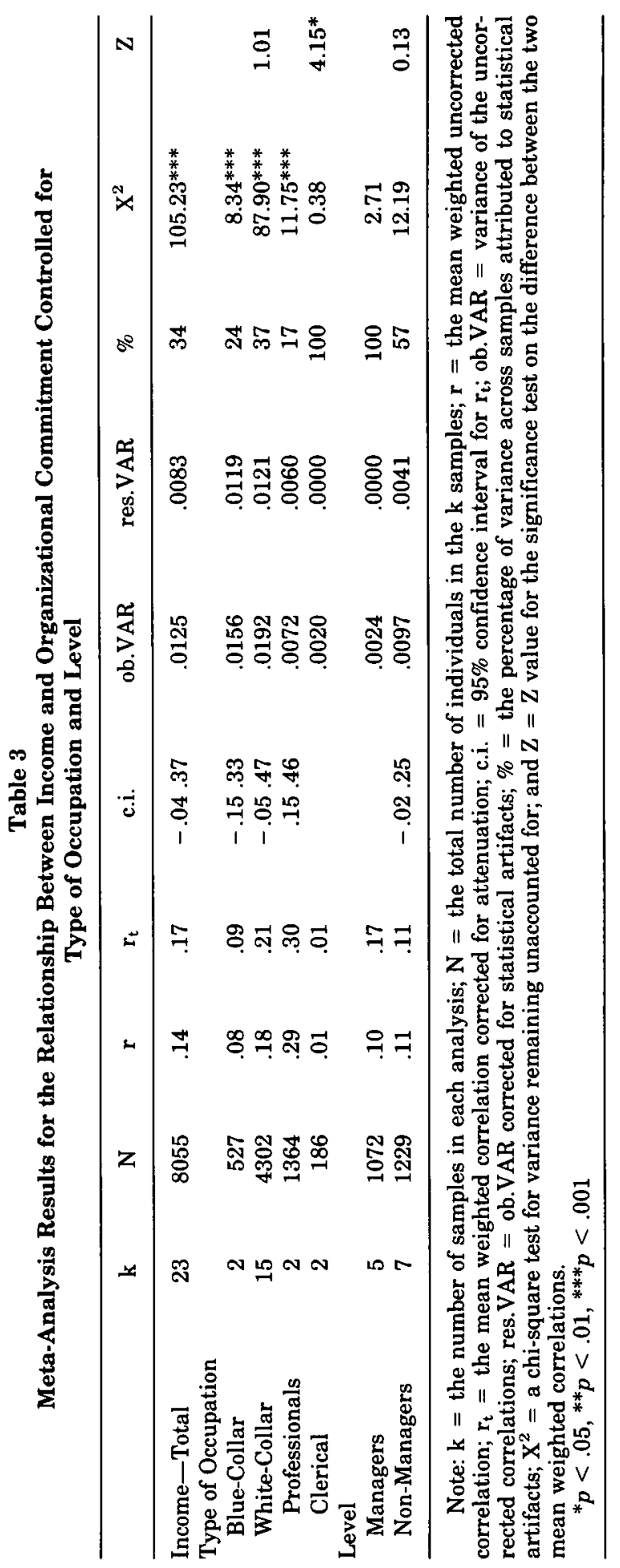


once again these coefficients are not significantly different $(z 0.90$; $p>.05)$. Although the correlation for clerical workers $(r=.38)$ is higher than the coefficient obtained for professionals $(r=.28)$, the difference between the two coefficients is not statistically significant $(z=0.90$; $p>.05$ ).

Results regarding level in the organization contradict Hypothesis 3 by showing a stronger relationship between $\mathrm{OC}$ and pay satisfaction for managers $(r=.40)$ than for non-managers $(r=.29)$. The difference, however, is not significant ( $z=1.37 ; p>.05$ ). In conclusion, although the correlations are higher for lower level occupations (i.e., blue-collar vs white-collar and clerical vs professionals), the differences are not statistically significant. Moreover, there is a stronger correlation for managers than for non-managers. But again, the difference between the two coefficients is not significant. Accordingly, the null hypothesis is not rejected.

Commitment and Pay Satisfaction Measures. Results in Table 5 show no meaningful effect of the measurement of $\mathrm{OC}$ upon the OC-actual income relationship. Differences in the correlations are found in the pay satisfaction-OC relationship. The correlation is higher for the attitudinal measures' subgroup of $\mathrm{OC}(\mathrm{r}=.44)$ than for the measure's subgroup of Porter et al. $(\mathrm{r}=.25)$. The difference between the correlations is statistically significant $(\mathrm{z}=1.97 ; \boldsymbol{p}<.05)$. Regarding the effect of the measurement of pay satisfaction, the results show a difference in the pay satisfaction-OC relationship between the JDI measure subgroup $(r=.17)$, and the other measures' subgroup $(r=.44)$. The difference is statistically significant $(\mathrm{z}=4.50 ; p<.05)$.

\section{DISCUSSION AND CONCLUSION}

The purpose of this paper was to examine the effects that income and pay satisfaction have upon $\mathrm{OC}$ across different structural settings. The weak relationship between these variables and $\mathrm{OC}$ found in main effect analyses (Cohen \& Lowenberg, 1990; Mathieu \& Zajac, 1990) suggested that income and pay satisfaction may operate differently across various structural settings.

The most significant finding is that the sector (private- versus public-sector organizations) has a moderating effect upon the pay satisfaction and OC relationship. As suggested in the organizational justice literature, pay satisfaction (outcome satisfaction) represents the individual's perceptions of the procedures used to determine pay and has been reported to relate to OC (Tyler, 1984). As predicted in Hypothesis 1 , the pay satisfaction and $\mathrm{OC}$ relationship is higher in private-sector 


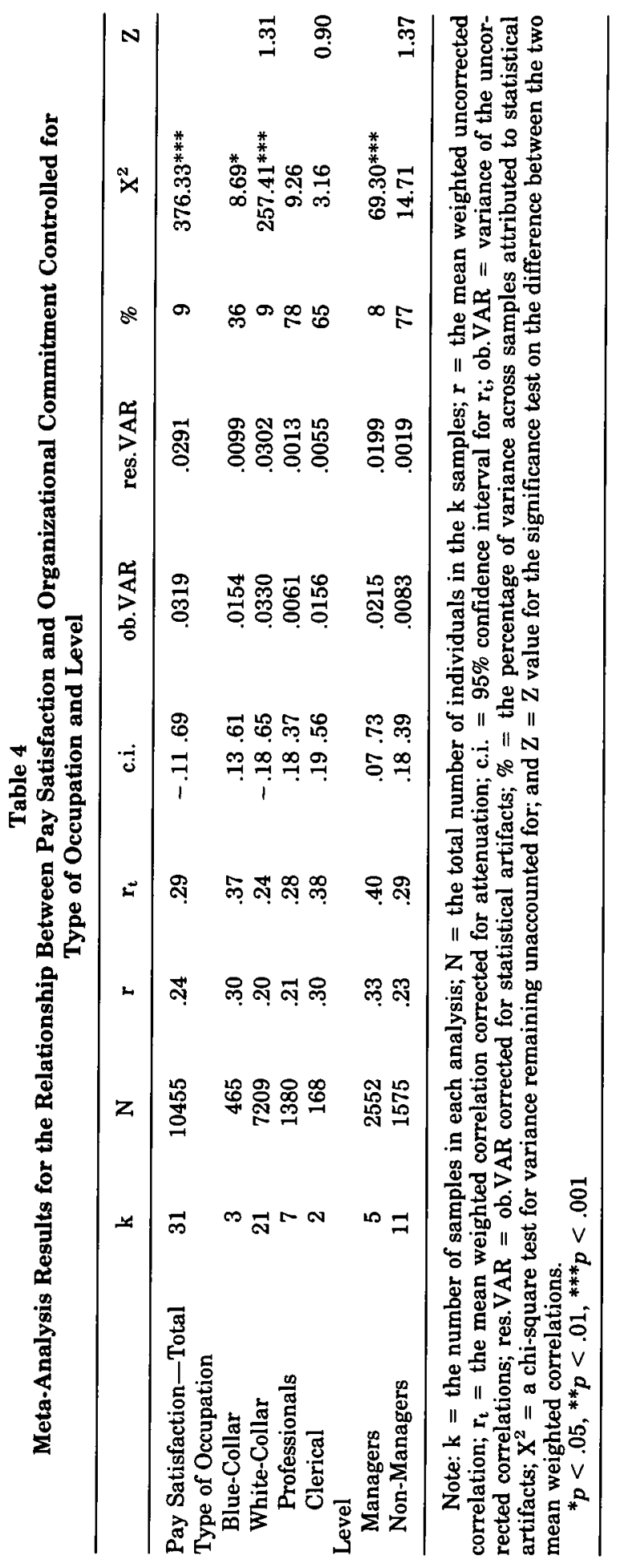




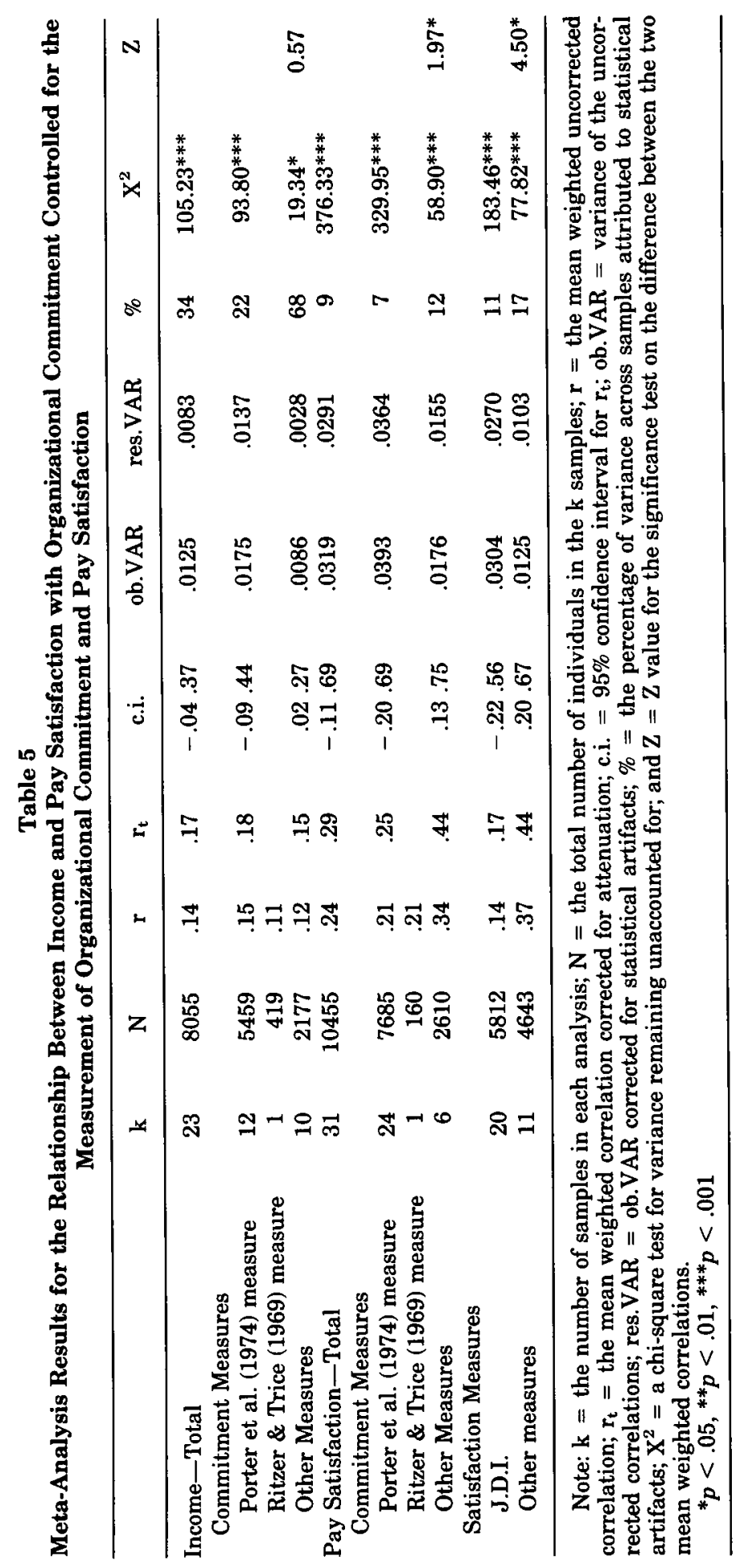


than public-sector organizations. This confirms the notion that privatesector employees have a better indication of how performance relates to rewards than public-sector workers. Thus, greater understanding of the procedures used to determine pay-levels in the private-sector increases OC-pay satisfaction relationship.

Although actual income relates positively to $\mathrm{OC}$ as suggested in the organizational justice literature (e.g., Greenberg, 1990), the difference between public and private-sector organizations is not significant. In contrast, this difference is significant for the pay satisfaction-OC relationship. One explanation could be the stronger calculative orientation in the private-sector (Wiener \& Vardi, 1980). Accordingly, our data suggest that private sector employees' higher expectations regarding their extrinsic rewards are met subjectively (pay satisfaction). Another explanation might be found in the greater dependence of private sector firms on performance data for determining compensation. In contrast, public sector firms tend to have strong internal labor markets, and rewards are often dependent upon job classification and bargaining (e.g., Huntley, 1991).

Another interesting finding is that the data provides partial support for the moderating effect of type of occupation upon the pay-satisfaction/actual income and OC relationship. Specifically, the relationship between income and $\mathrm{OC}$ for professionals is significantly higher than that obtained for clerical workers. These data challenge the common assumption that intrinsic considerations are necessarily more important for generating positive work attitudes and behaviors among professionals. In fact, for pay satisfaction, the correlations are stronger for lower status occupations. Organizational justice literature might explain this finding by the importance of the process by which the employee must perceive the procedures used for determining pay as fair and, thereby, satisfactory (e.g., Mandler, 1982; Greenberg, 1990). In turn, this should increase OC levels (Oliver, 1990). The data provide no support for the moderating effect of the level and the size of the organization upon the income/pay-satisfaction and OC relationship. Such findings are corroborated by other research which reports that these situational variables have little effect upon OC levels (Nystrom, 1990). The data suggest that perceptions of fairness may not differ according to organization size nor the level held by the individual within the organizational hierarchy. The findings here suggest that reward administration may be perceived as fair in large organizations just as in smaller ones. Accordingly, this finding adds to our knowledge on how perceptions of justice with regard to rewards (income and pay satisfaction) may affect attitudes (Greenberg, 1990).

The findings of this study show a differential effect between actual income versus pay satisfaction. Pay satisfaction has a stronger effect 
upon OC than actual income across most of the structural moderators. This finding demonstrates that perceptions of income are more important in their effect upon OC than actual income.

Another consideration for future research is the effect of the measurement of the two attitudinal variables ( $O C$ and pay satisfaction) upon the findings. The OC-pay satisfaction relationship is strongly affected by the way these two variables are measured. The results showed that using the more common measures of OC (Porter et al., 1974) and pay satisfaction (JDI) resulted in a smaller relationship in the OC-pay satisfaction relationship. The effect of the measures upon the findings is quite strong and poses some problems in generalizing the findings of this study. The problem is not only a methodological one, and is not whether this or another measure of $\mathrm{OC}$ or pay satisfaction should be applied. There is a need for a theoretical and conceptual reexamination of the definition and theory behind the measures of $\mathrm{OC}$ and pay satisfaction. This will assist in determining the conceptual implications of the different measures in terms of results interpretation and their practical implications. Only following such steps can a conclusion be reached as to which measures are the most appropriate for measuring these attitudes. The question of which measures analyzed in this study are more conceptually appropriate is beyond the scope of this research. At present, however, research regarding the OC-reward variables relationship cannot be interpreted or conducted without considering the effect of the measurements upon findings.

Finally, several limitations of the study should be mentioned. First, in some cases the results of the moderator analysis are based on only a few samples due to missing values-especially for the occupation moderator. Most of this problem was controlled for in this study by applying the Hunter and Schmidt (1990) test of difference between subgroups which is designed to test the significance of the difference between two groups that include a few cases of correlations. In addition, Hunter and Schmidt (1990) argued that if the number of studies in the analysis is small, conclusions about moderators can be only tentative. Firmer conclusions must await the accumulation of further studies. Second, the actual income and pay satisfaction variables are probably not the most important correlates of OC (Mathieu \& Zajac, 1990). It is likely that the rewards-OC relationships are affected by other moderators, such as career stages, which were not included in this study. However, this paper shows that attention in research design should be shifted from main effect analysis to moderating effects in exploring the relationships between reward variables and OC. Furthermore, more empirical research is needed to validate the results and conclusions of this study. In that regard, the arguments and findings of this study may be a good starting point. 


\section{REFERENCES}

Angle, H. L., \& Perry, J. L. (1981). Organizational commitment and organizational effectiveness: An empirical assessment. Administrative Science Quarterly, 26, 1-14.

Becker, H. S. (1960). Notes on the concept of commitment. American Journal of Sociology, $66,32-40$.

Cohen, A. (1991). Career stage as a moderator of the relationship between organizational commitment and its outcomes: A meta-analysis. Journal of Occupational Psychology, $64,253-268$.

Cohen, A., \& Lowenberg, G. (1990) A reexamination of the side-bet theory as applied to organizational commitment: A meta-analysis, Human Relations, 43, 1015-1050.

Greenberg, J. (1982). Approaching equity and inequity in groups and organizations. In J. Greenberg \& R. L. Cohen (Eds.), Equality and justice in social behavior (pp. 389-435). New York: Academic Press.

Greenberg, J. (1990). Organizational justice: Yesterday, today, and tomorrow. Journal of Management, 16, 399-432.

Guzzo, R., Jackson, S.E., \& Katzell, R.A. (1987). Meta-Analysis Analysis, In Cummings, L.L., \& Staw, B.M. (Eds.) Research in Organizational Behavior, 9, 407-442. Connecticut: JAI Press Inc.

Hodson, R., \& Sullivan, T. A. (1985). Totem or tyrant? Monopoly, regional and local sector effects on worker commitment. Social Forces, 63, 716-731.

Hundley, G. (1991). Public- and private-sector occupational pay structures. Industrial Relations, $30,417-434$.

Hunter, J. E., Schmidt, F. L., \& Jackson, G. B. (1982). Meta-analysis: Cumulating research findings across studies. Beverly Hills, California: Sage Publications.

Hunter, J.E., \& Schmidt, F.L. (1990). Methods of Meta-Analysis: Correcting error and bias in research findings. Beverly Hills, California: Sage Publications.

Idson, T. L., \& Feaster, D. J. (1990). A selectivity model of employer-size wage differentials. Journal of Labor Economics, 8, 99-122.

Mandler, G. (1982). The structure of value: Accounting for taste. In M. S. Clark \& S. T. Fiske (Eds.), Affect and cognition (pp. 3-36). Hillsdale, NJ: Lawrence Erlbaum.

Mathieu, J. E., \& Zajac, D, M. (1990). A review and meta-analysis of the antecedents, correlates and consequences of organizational commitment. Psychological Bulletin, $108,171-194$.

Moulton, B. R. (1990). A reexamination of the federal-private wage differential in the United States. Journal of Labor Economics, 8, 270-293.

Mowday, R. T., Porter, L. M., \& Steers, R. M. (1982). Employee organizational linkage. New York: Academic Press.

Nollen, S. D., \& Gaertner, K. N. (1991). Effects of skill and attitudes on employee performance and earnings. Industrial Relations, 30, 435-455.

Oliver, N. (1990). Rewards, investments, alternatives and organizational commitment: Empirical evidence and theoretical development. Journal of Occupational Psychology, $63,19-31$.

Pearlman, K., \& Schmidt, F. L., \& Hunter, J. E. (1980). Validity generalization results for tests used to predict training success and job proficiency in clerical occupations. Journal of Applied Psychology, 65, 373-406.

Pfeffer, J., \& Cohen, Y. (1989). Determinants of internal labor markets in organizations. Administrative Science Quarterly, 29, 550-572.

Porter, L. W., Steers, R. M., Mowday, R. T., \& Boulian, P. V. (1974). Organizational commitment, job satisfaction and turnover among psychiatric technicians. Journal of Applied Psychology, 59, 603-609.

Ritzer, G., \& Trice, H. M. (1969). An empirical study of Howard Becker's side-bet theory. Social Forces, 47, 475-479.

Salancik, G. R. (1977(A)). Commitment and the control of organizational behavior and belief. In B. M. Staw, \& G. R. Salancik (Eds.), New Directions in Organizational Behavior (pp. 1-54). Chicago, Ill.: St. Clair Press.

Salancik, G. R. (1977(B)). Commitment is too easy. Organizational Dynamics, 6, 62-80.

Schmidt, F. L., Hunter, J. E., \& Raju, N.S. (1988). Validity generalization and situational 
specificity: A second look at the $75 \%$ rule and the Fisher's z transformation. Journal of Applied Psychology, 73, 665-672.

Smith, P.C., Kendall, L.M., \& Hulin, C.L. (1969). The measurement of satisfaction in work and retirement. Rand-McNally. Chicago.

Wiener, Y., \& Vardi, Y. (1980). Relationships between job, organization and work outcomes: An integrative approach. Organizational Behavior and Human Performance, $26,81-96$.

\section{APPENDIX A}

\section{LIST OF THE STUDIES USED IN THE META ANALYSIS}

\section{Studies Used for the Variable "Income"}

Amernic, J. H., \& Aranya, N. (1983). Organizational commitment: Testing two theories. Relations Industrielles, 38, 319-341.

Baba, V. V., \& Jamal, M. (1979). On Becker's theory of commitment: An empirical verification among blue-collar workers. Relations Industrielles, 34, 123-137.

Baba, V. V., \& Knoop, R. (1987). Organizational commitment and independence among Canadian managers. Relations Industrielles, 42, 325-343.

Bluedorn, A. C. (1982). A unified model of turnover from organizations. Human Relations, $35,135-153$.

Brief, A. P., Van Sell, M. \& Aldag, R. J. (1978). Job scope-employee reaction relationships: Methodological considerations. Journal of Management, 4, 27-32.

Chelte, A. E., \& Tausky, C. (1986). A note on organization commitment. Work and Occupations, 13, 553-561.

Collarelli, S.M., \& Bishop, R.C. (1990). Career Commitment: Functions, correlates, and management. Group \& Organization Studies, 15, 158-176.

Glisson, C., \& Durick, M. (1988). Predictors of job satisfaction and organizational commitment in human service organizations. Administrative Science Quarterly, 33, 61-81.

Huselid, M. A. \& Day, N. E. (1991). Organizational commitment, job involvement, and turnover: A substantive and methodological analysis. Journal of Applied Psychology, $76,380-391$.

Jorde-Bloom, P. (1988). Factors influencing overall job satisfaction and organizational commitment in early childhood work environments. Journal of Research in Childhood Education, 3, 107-122.

Klein, K. J., \& Hall, R. J. (1988). Correlates of employee satisfaction with stock ownership: Who likes an ESOP most? Journal of Applied Psychology, 73, 630-638.

Koch, J. L., \& Steers, R. M. (1978). Job attachment, satisfaction and turnover among public sector employees. Journal of Vocational Behavior, 12, 119-128.

Loundsbery, J.W., \& Hoopes, L.L. (1986). A vacation from work: Changes in work and nonwork outcomes. Journal of Applied Psychology, 71, 392-401.

Martin, J. E., Magenau, J. M., \& Peterson, M. F. (1986). Variables related to patterns of union stewards' commitment. Journal of Labor Research, 7, 323-336.

Meyer, J. P., \& Allen, N. J. (1988). Links between work experiences and organizational commitment during the first year of employment: A longitudinal analysis. Journal of Occupational Psychology, 61, 195-209.

Michaels, C. E., \& Spector, P. E. (1982). Causes of employee turnover: A test of the Mobley, Griffeth, Hand \& Meglino model. Journal of Applied Psychology, 67, 53-59.

O'Reilly, C. A., \& Caldwell, D. (1980). Job choice: The impact of intrinsic and extrinsic factors on subsequent satisfaction and commitment. Journal of Applied Psychology, $65,559-565$.

Ritzer, G., \& Trice, H. M. (1969). An empirical study of Howard Becker's side-bet theory. Social Forces, 47, 475-479.

Still, L. V. (1983). Part-time versus full-time salespeople: Individual attributes, organizational commitment and work attitudes. Journal of Retailing, 59, 55-79. 
Summers, T. P. \& Hendrix, W. H. (1991). Modeling the role of pay equity perceptions: A field study. Journal of Occupational Psychology, 64, 145-157.

\section{Studies Used for the Variable "Pay Satisfaction"}

Aranya, N., Pollock, J., \& Amernic, J. (1981). An examination of professional commitment in public accounting. Accounting, Organizations and Society, 6, 271-280.

Barling, J., Wade, B., \& Fullagar, C. (1990). Predicting employee commitment to company and union: Divergent models. Journal of Occupational Psychology, 63, 49-61.

Brief, A. P., \& Aldag, R. J. (1980). Antecedents of organizational commitments among hospital nurses. Sociology of Work and Occupations, 7, 210-221.

Bruning, S. M., \& Snyder, A. R. (1983). Sex and position as predictors of organizational commitment. Academy of Management Journal, 26, 485-491.

Chacko, T.I. (1982). Women and equal employment opportunity: Some unintended effects. Journal of Applied Psychology, 67, 119-123.

Chassie, M. B., \& Bhagat, R. S. (1980). Role stress in working women: Differential effect on selected organizational outcomes. Group and Organization Studies, 5, 224-233.

Decottiis, T. A., \& Summers, T. P. (1987). A path analysis of a model of the antecedents and consequences of organizational commitment. Human Relations, 40, 445-470.

Elloy, D. F., Everett, J.E. \& Flynn, W. R. (1991). An examination of the correlates of job involvement. Group and Organization Studies, 16, 160-177.

Ettling, J. (1990). Winning and losing with ESOPS: The design of effective employee stock ownership plans. Academy of Management Proceedings, 269-273.

Griffeth, R.W., Hom, P.W., DeNisi, A.S. \& Kirchner, W.K. (1985). A comparison of different methods of clustering countries on the basis of employee attitudes. Human Relations, 38, 813-840.

Hollenbeck, J. R., \& Williams, C. R. (1986). Turnover functionally versus turnover frequency: A note on work attitudes and organizational effectiveness. Journal of Applied Psychology, 71, 606-611.

Hom, P. W., Katerberg, R., \& Hulin, C. L. (1979). Comparative examination of three approaches to the prediction of turnover. Journal of Applied Psychology, 64, 280-290.

Jauch, L.R., \& Sekaran, U. (1978). Employee orientation and job satisfaction among professional employees in hospitals. Journal of Management, 4, 43-56.

Jermier, J. M., Gaines, J., \& McIntosh, N. J. (1989). Reactions to physically dangerous work: A conceptual and empirical analysis. Journal of Organizational Behavior, 10, 15-33.

Konovsky, M. A., Folger, R. \& Cropanzano, R. (1987). Relative effects of procedural and distributive justice on employee attitudes. Representative research in Social Psychology, 17, 15-24.

Lavan, H., \& Banner, D.K. (1985). The perception of role conflict, role ambiguity and organizational commitment: differences between sexes. International Journal of Manpower, $6,32-35$.

Martelli, T. A., Waters, L. K., \& Martelli, J. (1989). The police stress survey: Reliability and relation to job satisfaction and organizational commitment. Psychological Reports, $64,267-273$.

McFarlin, D. B., \& Frone, M. R. (1990). A two-tier wage structure in a nonunion firm. Industrial Relations, 29, 145-154.

McGinnis, S. K., \& Morrow, P. C. (1990). Job attitudes among full and part-time employees. Journal of Vocational Behavior, 36, 82-96.

Morrow, P. C., \& McElroy, J. C. (1987). Work commitment and job satisfaction over three career stages. Journal of Vocational Behavior, 30, 330-346.

Norris, D. R., \& Niebuhr, R. H. (1983). Professionalism, organizational commitment and job satisfaction in an accounting organization. Accounting, Organization and Society, 9, 49-59.

Oliver, N. (1990). Rewards, investments, alternatives and organizational commitment: Empirical evidence and theoretical development. Journal of Occupational Psychology, $63,19-31$. 
O'Reilly, C. A., Bretton, G. E., \& Roberts, K. H. (1974). Professional employees' preference for upward mobility: An extension. Journal of Vocational Behavior, 5, 139-145.

Parasuraman, S. (1982). Predicting turnover intentions and turnover behavior: A multivariate analysis. Journal of Vocational Behavior, 21, 111-121.

Snyder, R. A., Verderber, K. S., \& Morris, J. H. (1986). Voluntary union membership of women and men: Differences in personal characteristics, perceptions and attitudes. Journal of Occupational Psychology, 59, 205-216.

Stone, E.F., \& Porter, L.W. (1975). Job characteristics and job attitudes: A multivariate study. Journal of Applied Psychology. 60, 57-64.

Welsch, H. P., \& Lavan, H. (1981). Inter-relationships between organizational commitment and job characteristics, job satisfaction, professional behavior and organizational climate. Human Relations, 34, 1079-1089.

Wiener, Y., \& Vardi, Y. (1980). Relationships between job, organization and work outcomes: An integrative approach. Organizational Behavior and Human Performance, 26, 81-96. 
Copyright of Journal of Business \& Psychology is the property of Springer Science \& Business Media B.V. and its content may not be copied or emailed to multiple sites or posted to a listserv without the copyright holder's express written permission.

However, users may print, download, or email articles for individual use. 